\title{
Twenty-four hour retention by neonates of an habituated heart rate response'
}

\author{
Rachel E. Keen, Helen H. Chase and Frances K. Graham \\ UNIVERSITY OF WISCONSIN
}

\begin{abstract}
Abstraet
Newborn heart rate consistently accelerated following an auditory stimulus of moderate intensity. With the long interstimulation interval employed, a brief 2-sec. stimulus elicited a brief acceleration which showed no decrement in 30 repetitions over two days. With a longer 10-sec. stimulus, the acceleration was initally prolonged and this prolonged acceleration diminished after a few repetitions. After a 24-hour interval, the 10-sec. stimulus continued to elicit only a brief acceleration in Ss with prior stimulation experience but elicited a prolonged response in age-controls.

\section{Problem}

Recent studies by Bridger (1961) and by Bartoshuk (1962) have reported a significant decrement in the heart rate response of neonates to repeated presentation of an unreinforced stimulus and have raised the question of whether or not this phenomenon represents a form of simple learning. The present study, by measuring cardiac activity continuously for approximately $20 \mathrm{sec}$. after stimulus onset, investigated changes in the form of the response with repeated stimulation. Long intervals between stimulations (ISI) were employed to permit full recovery to prestimulus responding. If full recovery is not allowed to occur, habituation might reflect tonic changes in activation level or an interaction between an incomplete response and a superimposed succeeding response. A second session of stimulation was given $24 \mathrm{hr}$. after the first to determine whether there were any persisting effects of the original habituation procedure, as might be expected from a learning interpretation. Duration of the stimulus was also varied since habituation should be a function of this variable (Sokolov, 1960; Bridger, 1961).

\section{Subjeets}

Forty fullterm, normal infants from the University Hospitals, Madison, Wisconsin, served as Ss. All infants born during the course of the study who met the normality, sex, and age criteria were selected. Parents of five infants refused permission; seven infants were replaced because of apparatus failure or external electrical interference; three because of experimenter error; and six because of crying, regurgitation, or movements which produced unreadable records.

\section{Method}

Twenty Ss were randomly assigned, 10 to each of two experimental groups which were tested for two successive days. Mean age was $42.4 \mathrm{hr}$. on the first day and $65.6 \mathrm{hr}$. on the second day. Half of the infants in each group were males. Subsequently, 20 additional
Ss, matched for sex and second-session age of experimental Ss, were assigned to two parallel control groups.

One experimental group received a $10-\mathrm{sec}$. stimulus on the first day and 2-sec. stimulus on the second day. The procedure was reversed for the second experimental group. The control group was similarly divided but was tested on one day only when the infants were the same age as second day experimental Ss. All Ss were given 15 trials per day with a 90 sec. ISI. Experimental sessions began within $2 \mathrm{hr}$. after a feeding. Arms and legs of Ss were swaddled to reduce movement and a pacifier was offered if $\mathrm{S}$ became restless. Before the first, sixth, and eleventh trials, two observers independently rated the infant's state along an eight-point continuum ranging from agitated crying to deep sleep.

The stimulus was a recorded rough-sounding buzz (300 clicks per sec.) which measured $75 \mathrm{db}$ at the site of the S's head. Stimulus durations and ISI were regulated by timers and the artifact was marked on a Gilson polygraph which also recorded the electrocardiogram and changes in thoracic circumference. The electrocardiogram was detected by suction electrodes attached 1.5 in apart in the midline of the chest and respiration, by a 1-in mercury strain gauge taped across the costal margins.

\section{Discussion}

Figure 1 shows curves of cardiac-period response on the first two trial-blocks for the experimental groups on Days 1 and 2. The scores are residual scores adjusted for regression on initial level. A downward deflection indicates acceleration and an upward deflection, deceleration.

In response to auditory stimulation, heart rate consistently accelerated within $2 \mathrm{sec}$. of stimulus onset
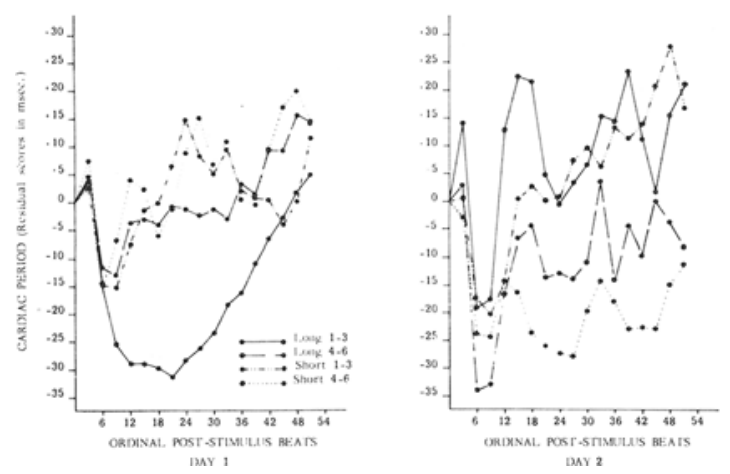

Fig. 1. Cardiac-period response on the first two trial-blocks following onset of a long (10-sec.) or a short (2-sec.) auditory stimulus. 
and, for the first few acceleratory beats, there was little difference as a function of trials or stimulus duration. After the first few beats, however, there was a marked difference on the first trial-block of the first day, depending upon whether the 10- or 2-sec. stimulus had been presented. Response to the 10-sec. stimulus was a prolonged acceleration which did not reach a peak until 16.5 beats while response to the 2-sec. stimulus achieved maximum rate at 8.4 beats. By trials four to six, the prolonged acceleration to the 10-sec. stimulus had habituated and did not differ from the response to the $2-\mathrm{sec}$. stimulus. There were no further decrements in response to either stimulus throughout the remaining nine trials on Day 1 or the trials on Day 2.

An analysis of the variance in number of beats to peak rate confirmed these observations. There was a significant effect of Duration (Day \& Order; $F=15.0$; $\mathrm{df}=1 / 162 ; \mathrm{p}<.001)$ and significant interactions of Trials $\mathrm{x}$ Days $(\mathrm{F}=5.4 ; \mathrm{df}=4 / 162 ; \mathrm{p}<.05)$ and Trials $\mathrm{x}$ Durations $(F=4.2 ; d f=4 / 162 ; p<.05)$. When these interactions were separated into orthogonal components, Trial-block 1 , in comparison with the remaining trialblocks, differed on the two days $(F=20.0 ; \mathrm{df}=1 / 162$; $\mathrm{p}<.001)$ and under the two durations $(\mathrm{F}=9.5 ; \mathrm{df}=1 / 162$; $\mathrm{p}<.01)$.

Control Ss, stimulated for the first time when they were the same age as Day 2 experimental Ss, performed like Day 1 experimental Ss (Fig。2). Statistical comparison confirmed that control and Day 1 experimental Ss did no $t$ differ and that control and Day 2 experimental Ss did differ in first trial-block response to the 10-sec. stimulus $(t-r a t i o=2.17 ; \mathrm{p}<.05)$. The control Ss also showed significant effect of Duration $(F=4.70 ; p<.05)$ and a significant interaction between Duration and the first trial-block compared to the remaining blocks $(\mathrm{F}=4.73 ; \mathrm{p}<.05)$.

Analyses of respiratory rate and prestimulus cardiac activity revealed no significant effect of trials, days, stimulus durations, or interactions of these variables, although there was a consistent increase in respiratory rate in the $5 \mathrm{sec}$. following stimulation. Behavioral ratings of state showed significantly greater arousal on the second day of testing and decreasing arousal during a single session but state did not vary with stimulus duration and could not, therefore, account for the initially greater response to the $10-\mathrm{sec}$. stimulus nor the retention of habituation on the second day.

The newborn heart rate response thus showed decrement, i. e., a shortened period of acceleration,

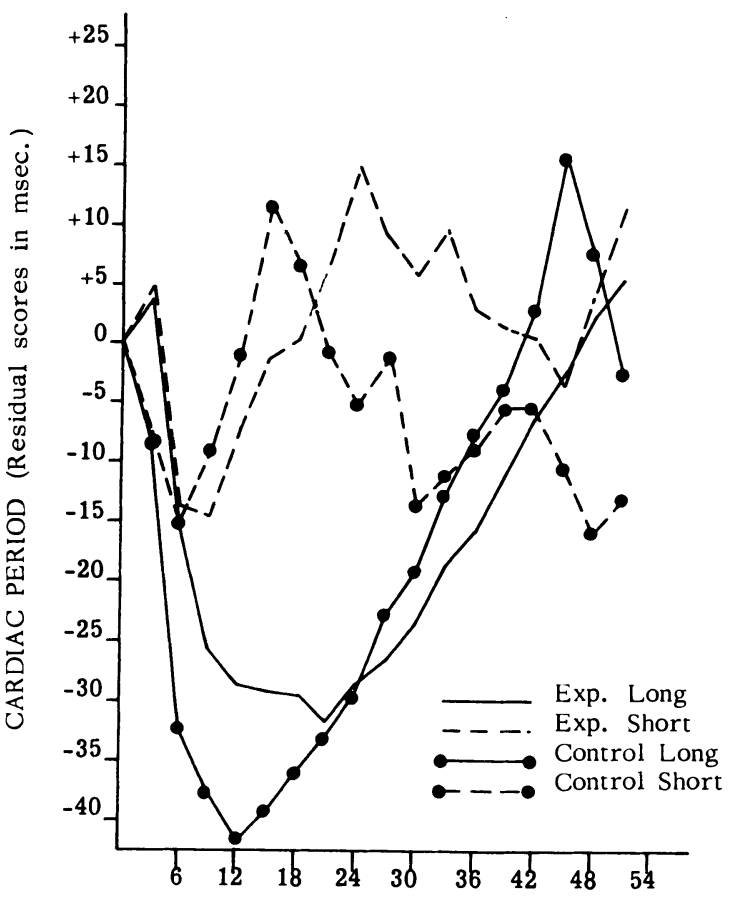

ORDINAL POST-STIMULUS BEATS

Fig. 2. Cardiac-period response of control and experimental groups on the first trial-block presentations of a long (10-sec.) or a short (2-sec.) auditory stimulus.

when a long (10-sec.) stimulus was repeated. The decrement occurred rapidly, within the first few trials, which is consistent with Russian reports (Sokolov, 1960) of rapid habituation of the orienting response in adult Ss. There was no habituation, however, of the briefer acceleratory response to a short (2-sec.) stimulus. It appears that habituation to tone onset may be difficult to obtain but that habituation to the prolongation of stimulation occurs rapidly and persists for at least $24 \mathrm{hr}$.

\section{Heferences}

BARTOSHUK, A. K. Response decrement with repeated elicitation of human neonatal cardiac acceleration to sound. J.comp. physiol. Psychol., 1962, 55, 9-13.

BRIDGER, W. Sensory habituation and discrimination in the human neonate. Amer. J. Psychiat., 1961, 117, 991-996.

SOKOLOV, E. N. Neuronal models and the orienting reflex. In M.A.B. Brazier (Ed.), The central nervous system and behavior. New York: Josiah Macy, Jr. Foundation, 1960.

Note

1. This research was supported by grants No. MH-02011 and K3-MH21,762 from the National Institute of Mental Health and by a Public Health Postdoctoral Fellowship to the senior author. 